\title{
Children's Health Insurance in New Hampshire: An Analysis of New Hampshire Healthy Kids
}

\author{
BY SALLY K. WARD, SARAH SAVAGE, AND NENA STRACUZZI
}

\section{Introduction}

New Hampshire has been successful in achieving one of the lowest uninsurance rates for children in the country-6 percent in 2005 (US Census). The extent to which New Hampshire Healthy Kids has contributed to New Hampshire's success in achieving this low rate is the focus of this brief.

The social and economic environment in New Hampshire is conducive to health insurance coverage for children in several important respects. There is consensus among the general public that children should be covered, the state has a very high rate of employer-sponsored insurance, and the combined Healthy Kids programs provide a key safety net for low and moderate income families and children.

As part of this research, we asked a sample of New Hampshire residents about children's health insurance. ${ }^{1}$ An impressive 86 percent of respondents indicated that uninsured children should be covered by a publicly supported health insurance program. This is an important indicator of the support for children's health insurance coverage.

Further, New Hampshire has one of the highest rates of Employer Sponsored Insurance (ESI) coverage for children in the nation. In 2005, 77 percent of children in New Hampshire had this type of coverage (US Census). New Hampshire businesses appear to value coverage, and until recently have consistently been able to build this into their compensation packages. There is some indication, however, that the ESI rate has slipped in recent years, which is part of a nationwide trend.

The third factor conducive to decreased numbers of uninsured children is the Healthy Kids programs for low and moderate income children, the focus of this brief. Currently, approximately 70,000 of New Hampshire's children are covered through one of the Healthy Kids programs.

\footnotetext{
${ }^{1}$ This question was part of a Granite State Poll commissioned for this brief.
}

It is important to note that although New Hampshire's State Children's Health Insurance Program (SCHIP) is often confused with New Hampshire Healthy Kids, this research is not an analysis of SCHIP. Rather, this research attempts to assess the contribution of New Hampshire Healthy Kids to the state's low rate of uninsured children. Since there is often confusion about the meaning of "Healthy Kids," it is important to clarify several facts about New Hampshire Healthy Kids:

1. There are different meanings to "New Hampshire Healthy Kids."

\section{It is an "umbrella" term used to refer to three distinct health insurance programs for children:}

- Healthy Kids GOLD (Medicaid)

- Healthy Kids SILVER, for low-income families whose incomes exceed Medicaid eligibility limits

- Healthy Kids BUY-IN, the non-subsidized option for families with moderate incomes

It is a nonprofit corporation established in 1993 by the New Hampshire Legislature, governed by a Board of Directors, and managed by CEO and President Tricia Brooks, hired in 1994.

From this point on in the brief, "Healthy Kids" will be used to refer to the programs, while "NHHK" will be used to refer to the corporation.

2. Healthy Kids SILVER is the New Hampshire State Children's Health Insurance Program (SCHIP).

3. Healthy Kids SILVER covers 7,000 children, just 10 percent of all Healthy Kids enrollments, and accounts for less than 1 percent of the NH Department of Health and Human Services (DHHS) budget. 
4. Funding and support for Healthy Kids come from many different sources: foundations, state funds, federal contributions, premiums paid by parents/guardians, and in-kind donations and discounts from health care providers and the insurance industry.

5. NHHK has some but not total control over features of the program(s); DHHS and the state legislature also have authority to make decisions that affect Healthy Kids.

Although some of the success in insuring children in the state is a product of the social and economic context in New Hampshire, NHHK also plays a role. The characteristics of NHHK that help account for its contribution to the state's success include:

- An established track record that predated the creation of SCHIP;

- the integration of different programs under one "brand name," creating a seamless approach for families;

- the corporation's independent, nonprofit status, facilitating an innovative approach that is mission driven and strategic; and

- an investment in partnerships with organizations and providers throughout the state, ranging from the Department of Health and Human Services (DHHS) to individual physicians.

\section{About the Research}

The multi-method approach used for this research consisted of both qualitative and quantitative components. To provide a context for NH's success, data from the US Census Current Population Survey were analyzed. In order to assess program scale, Healthy Kids enrollment data were examined. In-depth interviews were conducted with twenty-nine professionals in the fields of family resources, health care, and community health; resource specialists were also interviewed. The interviews enabled the research team to understand the nuances of the way NHHK functions, which a comprehension of the program and policies alone could not. Lastly, two surveys were conducted by the UNH Survey Center to gain a systematic understanding of the awareness, perceptions, and support of Healthy Kids among $\mathrm{NH}$ residents and school nurses. A random sample of residents was contacted via telephone as part of a Granite State Poll. A web-based survey was emailed to a listserv of school nurses managed by the School Nurse Association.

\section{Background to the New Hampshire Healthy Kids Program}

Between 1977 and 1987, the percentage of children without any form of health insurance in the United States increased by 40 percent, according to estimates based on the Current Population Survey (CPS). Florida was one of the earliest states to address this increasing problem of uninsured children. Dr. Steve Freedman, a public health expert in the state, published an article in the New England Journal of Medicine (1988) proposing a school-based health insurance program for children who did not qualify for coverage under Medicaid. Freedman argued that the cost of health insurance could be reduced for children by grouping them together through their schools, much like large employers buy group health coverage for their employees at lower costs. In 1990, the Florida legislature acted on Freedman's suggestions by creating the Florida Healthy Kids Corporation, a public-private agent of change in the health insurance marketplace.

New Hampshire followed in 1993 with NHHK, a 501(c)(3) nonprofit corporation governed by a volunteer board of directors, and by 1994, headed by CEO, Tricia Brooks. The legislature appropriated $\$ 240,000$ in seed money, with the intention that NHHK would become self-sustaining. Brooks determined that the program would need to enroll at least 4,000 children in order to operate independently; by the end of their second year however, with only 1,600 children enrolled, NHHK was far from self-supporting.

The situation in New Hampshire and nationwide changed dramatically in 1997 when the State Children's Health Insurance Program (SCHIP) was enacted at the federal level through Title XXI of the Social Security Act. SCHIP was intended to provide coverage for the millions ${ }^{2}$ of uninsured children from families with incomes that were above Medicaid's eligibility standards, yet not high enough to afford private coverage. About $\$ 40$ billion in federal funds for SCHIP was appropriated over the ten-year period from 1998 to 2007. Since New Hampshire had already established NHHK, the decision was made that it would be the appropriate organization to implement SCHIP in the state.

\section{The New Hampshire Healthy Kids Model}

New Hampshire was fortunate that when SCHIP funds became available, NHHK already had an established infrastructure and operating capabilities. In New Hampshire, SCHIP funds were used to expand and improve NHHK, enabling the organization to strengthen its evaluation and marketing/outreach capabilities.

\footnotetext{
${ }^{2}$ The Congressional Budget Office estimated that SCHIP would cover 2.8 million uninsured children ineligible for Medicaid (Henderson and Coopey 2000).
} 


\section{New Hampshire Healthy Kids Programs}

Healthy Kids GOLD (Medicaid) provides coverage at no cost to children with family incomes up to 185 percent of the Federal Poverty Level. Children receive free coverage through providers who contract with the Department of Health and Human Services.

Healthy Kids SILVER offers low-cost health insurance with premiums of $\$ 25$ or $\$ 45$ per child, per month for families with incomes of up to 300 percent of the Federal Poverty Level. Co-payments apply to certain services and range from $\$ 5$ to $\$ 50$. Coverage is provided through Anthem Blue Cross Blue Shield and Northeast Delta Dental.

Healthy Kids BUY-IN is supported by provider discounts, in-kind donation of administrative insurance fees, and premiums paid by families. There is no government subsidy. Premiums are $\$ 146$ per child per month, and income eligibility is up to 400 percent of the Federal Poverty Level. Families "buy-in" to HK Silver.

In 2001, NHHK formed an alliance with the New Hampshire Department of Health and Human Services (DHHS) and began coordinating application assistance and outreach for Medicaid, promoted as "Healthy Kids Gold". The Gold program continued to provide coverage at no cost to children eligible for Medicaid. Another program option, "Healthy Kids Silver," was supported by SCHIP funds. Silver enables children from families with more moderate incomes to receive low-cost coverage with premiums. A third program option, "Healthy Kids Buy-in," was offered to families with incomes exceeding the Gold and Silver eligibility limits (see box above for program details).

As a result of these three Healthy Kids Programs, New Hampshire families have greater options available to them than families in many other states. Expansions to the program since SCHIP have included extending medical benefits to pregnant women, infants and toddlers as well as adding dental benefits.
Figure 1 shows the enrollments in Healthy Kids Silver and Buy-In between 1995 and 2005 (prior to SCHIP funding, NHHK's program was referred to simply as Healthy Kids). As shown, enrollments have more than doubled (and in the case of the Silver program, more than tripled) since the infusion of SCHIP funds.

Figure 2 shows enrollments from $2001-2005^{3}$ in the three programs. Altogether, Healthy Kids now helps more than 70,000 children gain access to free or low-cost health insurance on an annual basis. Although the majority of those served are enrolled in Healthy Kids Gold (Medicaid), as of $2005,7,000$ children have health care coverage who would

\footnotetext{
${ }^{3}$ New Hampshire Healthy Kids was only able to provide enrollment data for Healthy Kids Gold starting in 2001. DHHS was unable to track down the pre-2001 data in time for the completion of this report. While the CPS collects data on Medicaid coverage of children, its numbers are considerably underreported relative to administrative numbers (SHADAC 2001).
}

Figure 1. Number of NH Children Enrolled in Healthy Kids by Program Type Since NHhK was Established

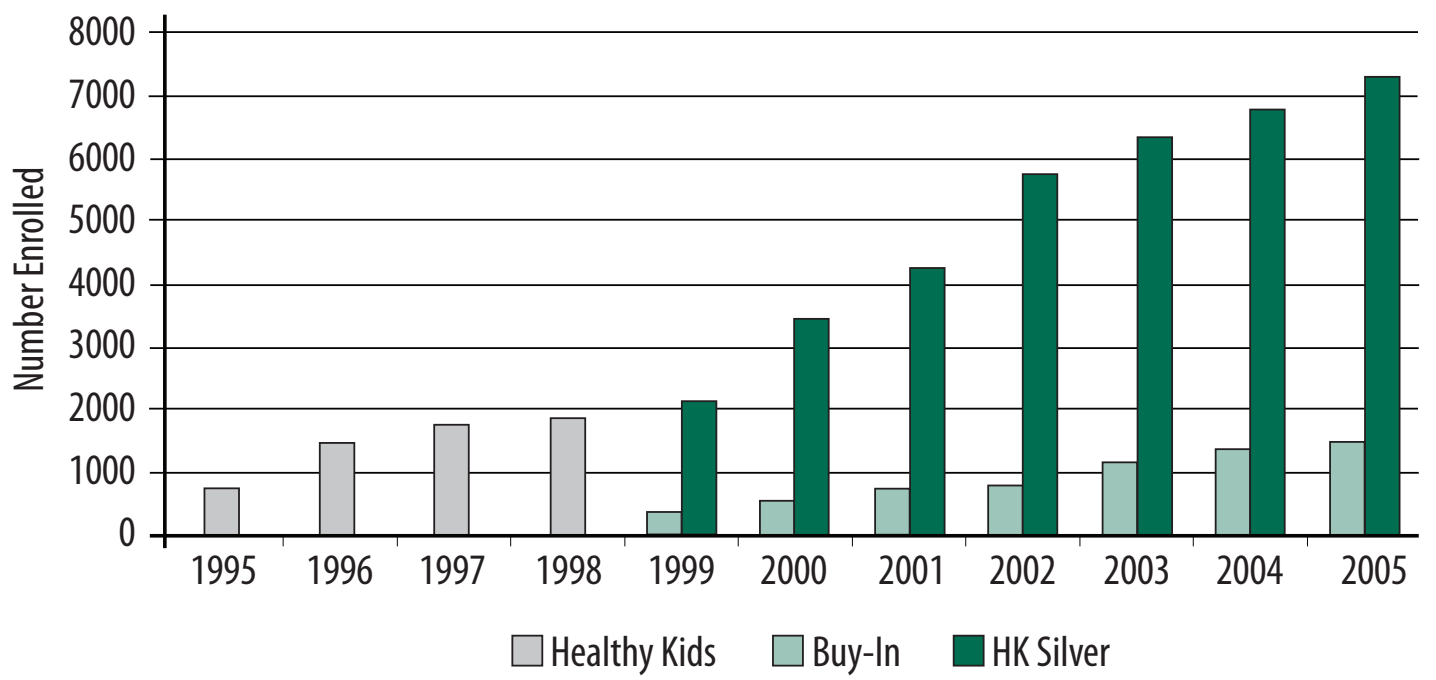

Source: New Hampshire Healthy Kids 
Figure 2. Number of Children Enrolled in Healthy Kids by Program Type Since NHHK and DHHS Partnered

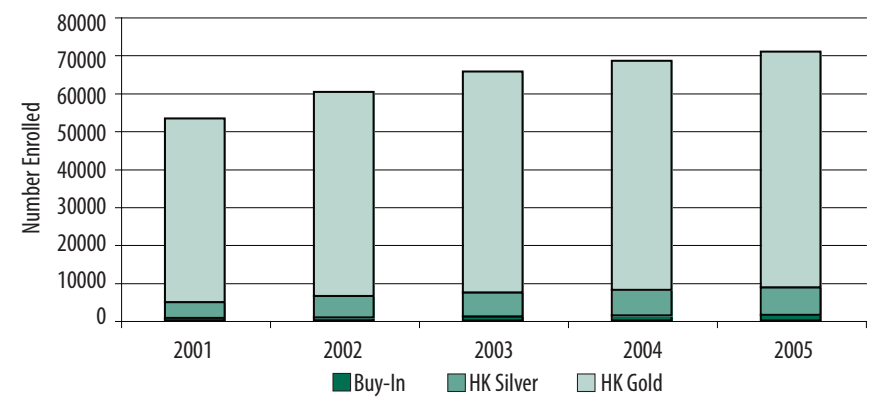

Source: New Hampshire Healthy Kids

otherwise likely be uninsured. Both Gold and Silver enrollments have grown since SCHIP; it is probable that through NHHK's outreach efforts to identify uninsured children, Healthy Kids Gold began covering more eligible children than prior to SCHIP, a pattern found in other states (Kenney and Chang 2004).

\section{Indicators of Success in Covering Children in New Hampshire}

To examine New Hampshire's success in providing children with health insurance coverage, we analyzed Current Population Survey (CPS) data from the US Census. In addition to showing that $\mathrm{NH}$ has achieved one of the lowest uninsurance rates of children in the country, it also offers some insight into what might account for that success. We also examined knowledge of Healthy Kids among adults in the state, as- suming that knowledge of the programs indicates successful outreach efforts. First we present US Census data, followed by survey data from adults in New Hampshire.

\section{The Percentage of Children Uninsured: How Does New Hampshire Compare to Other States?}

To assess how New Hampshire is doing, it is useful to compare its uninsurance rate with that in other states and the nation as a whole over time (see Figure 3). Key policy changes related to insurance for children are marked on the figure as well. Since the creation of NHHK, the uninsured rate in $\mathrm{NH}$ has been consistently lower than the national rate, and since SCHIP and the partnership between NHHK and DHHS, this rate has declined from 10 percent to 6 percent.

It should be noted that CPS estimates can be less precise for less-populated areas (Dubay, Hill, and Kenney 2002), so it is useful to look at averages in the uninsured rate over multiple year periods. Figure 4 shows the uninsured rate using three-year averages for all children and for low-income children; 6 percent of New Hampshire children under age 18 were without health insurance between 2003 and 2005, compared with a three-year average of nearly 12 percent for all U.S. children. This consistently lower uninsured rate holds true for all children as well as low-income children (at or below 200 percent of the federal poverty level).

It is also informative to see how New Hampshire compares with other states that have seen some success in covering children. We identified a set of states that are "top performers" in this regard. ${ }^{4}$ Figure 5 presents the data for

\footnotetext{
${ }^{4}$ In selecting top performers for the comparison, we used the following criteria: 1) a decline in the rate of uninsured children of $30 \%$ or greater between 1993 and 2005, and 2) a recent uninsured rate that is among the lowest across all states. Including change over time in rates help to rule out economic conditions or demographic characteristics in the states that might affect insurance rates.
}

\section{Figure 3. Uninsured Rate OF ChILdRen Under 18: NH AND US, 1987-2005}

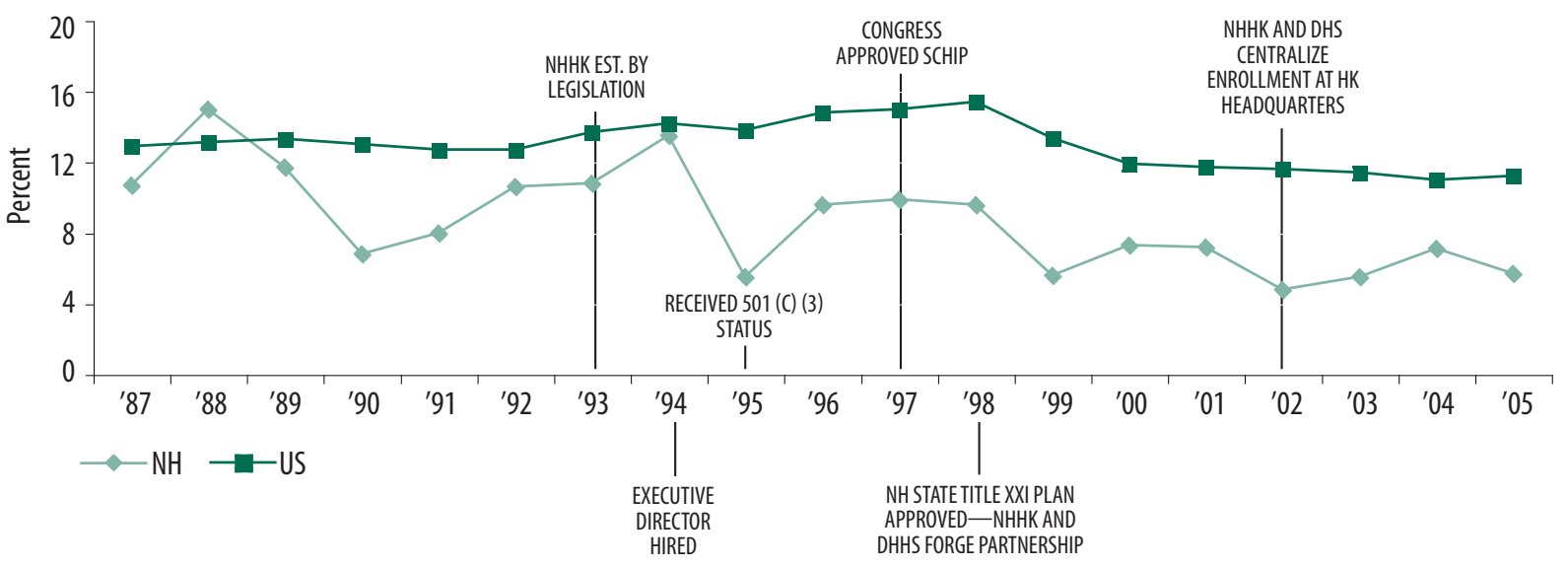


Figure 4. Percent of All Children (Under 18) and Low Income Children (Under 19) without Health INSURANCE BY ThreE-YeAR AVERAges: NH AND US

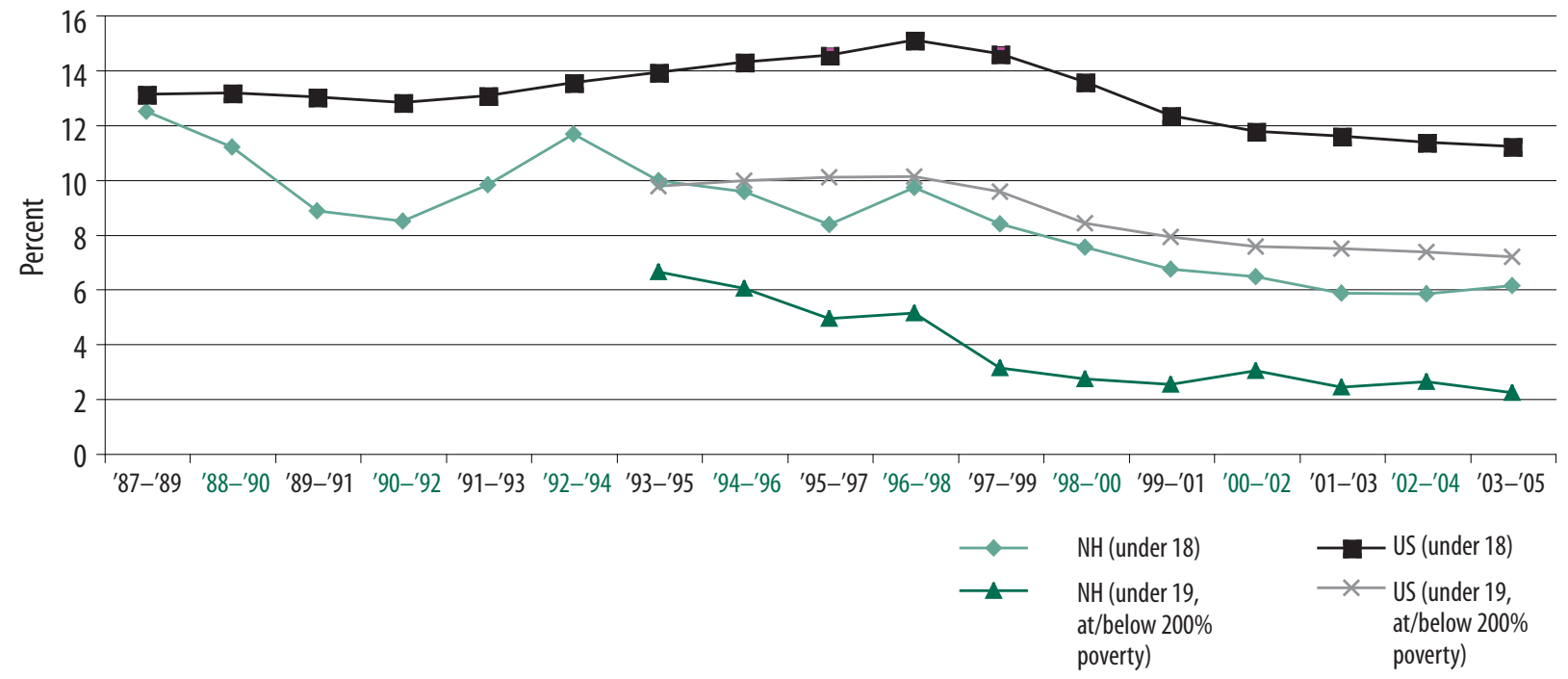

Source: US Census Current Population Survey March Supplement

the ten top performing states, including New Hampshire. In the earlier period (1993-1995), New Hampshire was in the middle of the top-performing states, but a decade later, it was among the top three performing states. Only Vermont and Michigan had lower rates of uninsured children over the three-year period from 2003-2005 (US Census).

An important factor influencing the percentage of uninsured children in any state is its employer-sponsored insurance rate (ESI). Figure 6 shows that, among the states identified as top performers, New Hampshire stands out with a consistently higher rate of ESI compared to the average for the other nine states. Even in New Hampshire however, there is a decline in ESI in the most recent years. Considering that
Healthy Kids enrollment data presented earlier showed that coverage increased yearly since 2000 , at the same time that ESI has declined, it appears that Healthy Kids has protected children from the recent downturn in ESI rates.

Because states vary widely in social and demographic characteristics, a second set of comparisons places New Hampshire in a comparable demographic context-the New England region. As Figure 7 shows, Vermont and New Hampshire are unique among the six New England states in that they experienced a steady decline in uninsured children between 1987 and 2005. Since New England states possess common social and economic characteristics, it is likely that a factor other than a favorable economy or particular

Figure 5. Uninsured Children in Ten States with a Low Uninsured Rate and a 30\%+ Reduction in UNINSURED CHILDREN, 1993-1995 TO 2003-2005 (THREE YEAR AVERAGES)

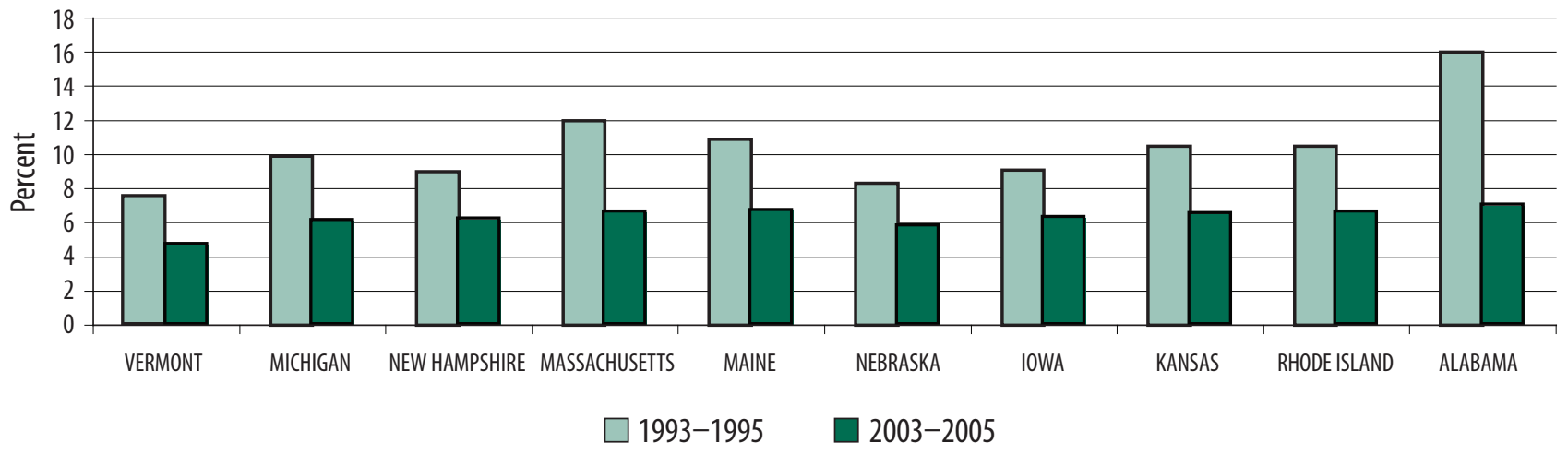

Source: US Census Current Population Survey March Supplement 
Figure 6. Rates of Children (UNDer 18) Covered by Employer Sponsored INSURANCe over Time Among Top Ten Performing States

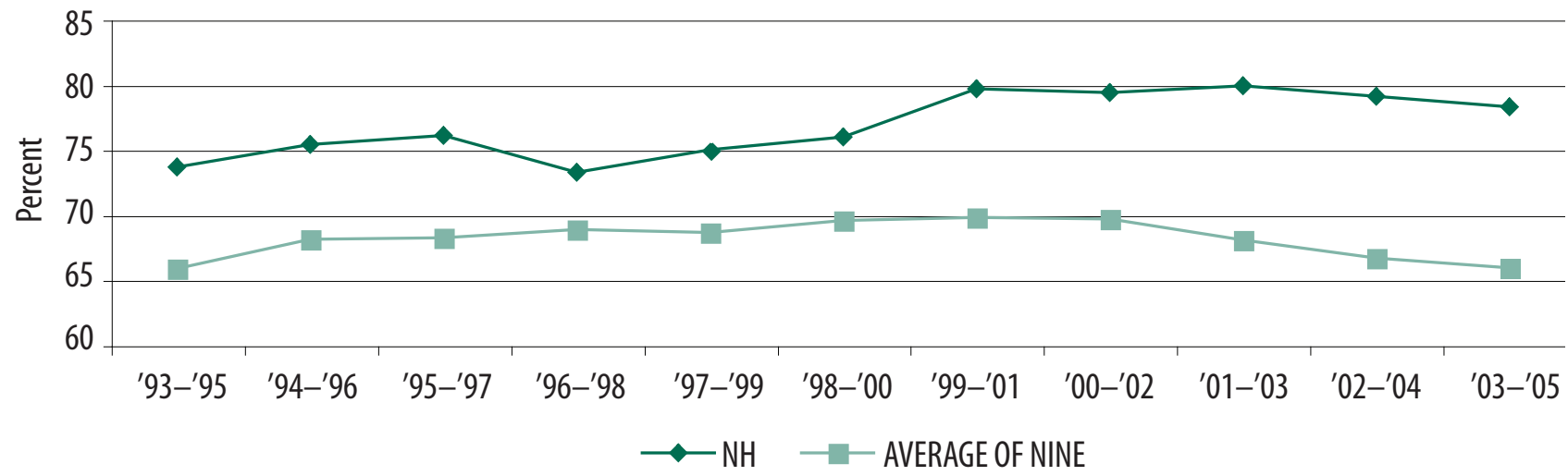

Source: US Census Current Population Survey March Supplement

demographic mix accounts for the decline in uninsured children in Vermont, and especially in New Hampshire, which experienced the largest decline.

One might assume that an increase in ESI over this same time frame would explain the decline in the uninsured rate (see Figure 6). However, this increase in ESI does not fully explain the magnitude of the decrease in the uninsured rate, as measured by the absolute or relative percentage change. For instance, from the period of 1987-1989 to that of 20032005, rates of ESI in New Hampshire increased from 73 percent to 78 percent, a 7 percent increase (5 percentage points), whereas the uninsured rate decreased from 13 percent to 6 percent, a 54 percent decrease ( 7 percentage points).

Given that New Hampshire consistently ranks high, even among states in its region, and given that ESI cannot fully account for this decline, we suggest that NHHK contributed to the decline in the uninsured rate of New Hampshire's children. This finding is strengthened by our multi-method approach as demonstrated by corroborating evidence from interviews and survey results.

Knowledge of Healthy Kids Among New Hampshire Residents

Another indication of the success of NHHK is provided by results from a survey of the residents of New Hampshire. In a Granite State Poll telephone survey ${ }^{5}$ conducted by the UNH Survey Center of a random sample of $507 \mathrm{NH}$

\footnotetext{
${ }^{5}$ The UNH Survey Center uses a random digit dialing method to reach a random sample of $\mathrm{NH}$ residents (18 years of age or older) for interviews. Telephone interviews were completed with $507 \mathrm{NH}$ adults from a sample of 4,878 randomly selected telephone numbers, for an overall response rate of $20 \%$ (this calculation is based on the American Association for Public Opinion Response Rate 3).
}

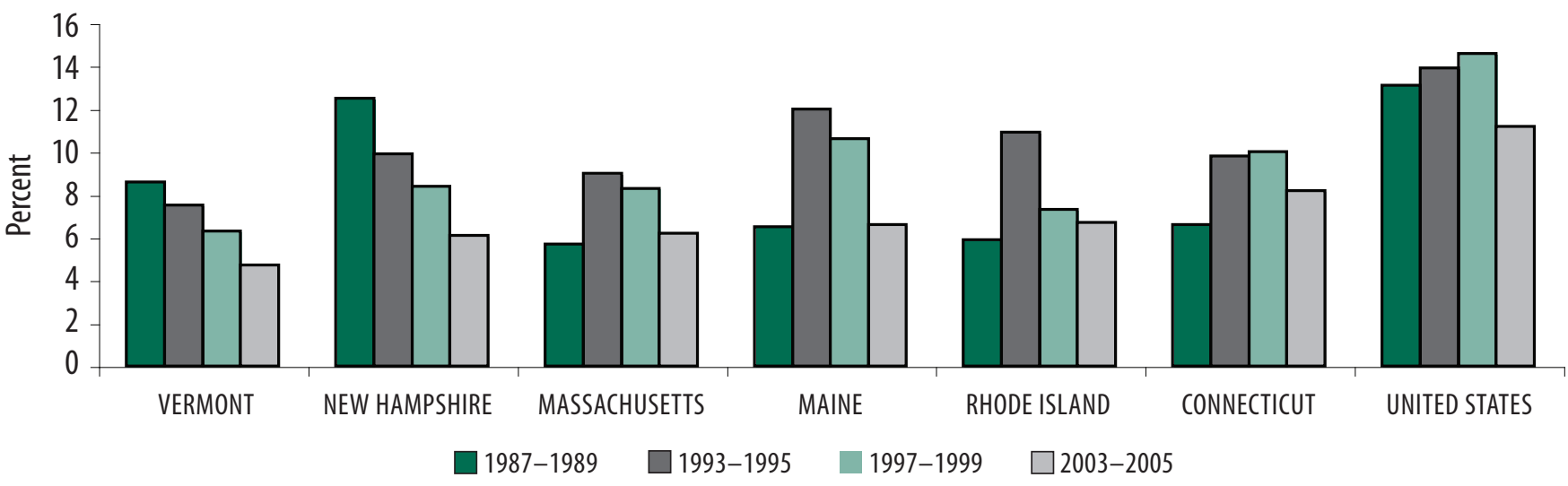

Source: US Census Current Population Survey March Supplement 
residents, awareness and usage of Healthy Kids was assessed among 183 respondents with children. We found that nearly two-thirds (67 percent) of respondents with children are familiar with Healthy Kids. Furthermore, when we asked respondents how they had learned about Healthy Kids, the largest percentage (27 percent) indicated they had heard about the program from a family member or a friend. This is an impressive level of awareness and knowledge about Healthy Kids. We also asked respondents how their children were covered. The largest percentage of respondents report coverage through an employer (77 percent), which is consistent with the high level of ESI in the state. The second highest percentage report coverage through Healthy Kids, at 12 percent.

\section{The Role of NHHK in the State's Success}

\author{
"Healthy Kids is obviously a huge success." \\ "Healthy Kids is doing exactly what a government program \\ should do, and it works."
}

"Healthy Kids has made incredible progress in insuring children."

"Healthy Kids is an extremely successful program-a model in this country for an effective state program that helps provide children with health insurance."

These comments from some of the interviews conducted for this brief ${ }^{6}$ indicate that the Healthy Kids model has a solid reputation and enjoys widespread support. Furthermore, the data suggest four important NHHK characteristics that contribute to New Hampshire's success in achieving a low rate of uninsured children:

- NHHK's established track record predating the creation of SCHIP;

- the integration of different programs under one "brand name";

- the independence of NHHK; and

- the investment in partnerships with organizations and providers throughout the state.

\footnotetext{
${ }^{6}$ Health and family resource professionals across the state of New Hampshire were interviewed for this study.
}

\section{An Established Track Record Before SCHIP}

According to the literature, in order to access SCHIP funds, states could choose between three approaches available to them under federal guidelines. States could expand Medicaid to cover children eligible for SCHIP; set up a separate program for SCHIP coverage through private insurers; or adopt a plan that combined Medicaid expansion with a new or existing program. New Hampshire established its SCHIP as a combination program, expanding Medicaid eligibility as well as building on NHHK's existing program for covering children from families whose incomes exceed the Medicaid eligibility limit.

As noted, because NHHK existed prior to the distribution of SCHIP funds and already had an infrastructure and operating capabilities, challenges associated with establishing an entirely new program were minimized. As a result, the transition to the new environment created by SCHIP funds was more efficient in New Hampshire, unlike a number of states that could not even access their SCHIP funds until the following year as they had to launch an entirely new program. NHHK's history and alliance with DHHS led to seamlessness on the processing end, which ultimately benefited the population served by Healthy Kids.

\section{The Integration of Different Programs under One "Brand Name"}

Although Medicaid was separated from welfare in 1996, the image of Medicaid as a welfare program persists, suggesting that there may be stigma associated with receiving Medicaid. Several factors in New Hampshire, however, help to limit this stigma. Health coverage for low- and moderate-income children, for example, is integrated under the Healthy Kids "brand;" families apply for Healthy Kids coverage, not for a particular program type. Indeed, most people know Healthy Kids only as a children's insurance program. This unified brand identity has had the effect of further reducing the percentage of children without health insurance, as enrollments in Healthy Kids Gold and Silver both increased after 1998. As suggested earlier, the application of NHHK's strategies to identify eligible uninsured children naturally led to identifying additional eligible children for the Gold program (Medicaid), which has been noted as a national trend more generally (Kenney and Chang 2004).

In addition, housing certain administrative offices of the three separate programs under one roof has created a seamless experience for applicants and has improved coordination and communication across programs. This also helps prevent children from slipping through the cracks or losing coverage prematurely, for instance, if a family's economic circumstances suddenly change. This was supported by a health policy specialist we interviewed, who claimed that even more important than program structure, per se, is creating a 
"seamless" system "through good coordination and communication between programs." Because DHHS and NHHK staff members are housed together in the NHHK offices in Concord, their working partnership to process applications and determine eligibility is reinforced by day-to-day working relationships.

\section{New Hampshire Healthy Kids Corporation:} Independent and Mission-driven

One theme that emerged from the interviews is that NHHK is innovative and persistent in pursuit of its mission. Unlike larger organizations with more multidimensional objectives, NHHK is very focused in its mission "to provide access to affordable quality health coverage for New Hampshire's uninsured children." Its size is linked to its focused mission and the focused mission is linked to its success. As one interviewee commented, NHHK is "very small, very valuable, and very important."

With a clear mission, the corporation has been able to be innovative in its approach. A good example is the organization's extensive outreach efforts. NHHK has been unremitting in trying to locate uninsured children and in offering training throughout the state for those who help families apply. Health care workers and family resource center staff we interviewed consistently commented about the contact, cooperation, and assistance of NHHK staff. According to one health services worker "Healthy Kids is extremely proactive in identifying remaining uninsured children....They do not simply wait for families to call." As noted above, twothirds of survey respondents were familiar with Healthy Kids programs, which is likely a result of these extensive outreach efforts.

Another example of innovation is the application process. The complexity of the application process can be a barrier for enrolling eligible children; NHHK staff knows this and works extensively with partners to maximize completion of applications. For instance, NHHK used grant funds to hire a literacy expert to assist with the creation of an application that would be easier for families to understand and complete. NHHK has also experimented with an over-the-phone application to determine whether customer service assistance would facilitate the process and lead to more completed applications.

New Hampshire is a relatively homogeneous state; however, there are significant pockets of ethnic groups, particularly in the urban southern tier, including the city of Manchester. Several of the health services workers we interviewed specifically cited the language barrier created by English-only written material. To reach this segment, NHHK has worked with the NH Minority Health Coalition in Manchester to develop methods of connecting with non-English speaking families. NHHK has developed a Spanish version of the application form to help address this barrier.

\section{The Investment in Partnerships}

One criterion for a "high performance" nonprofit organization is the development of an adaptive capacity: "staying informed of whether the mission is relevant and well-delivered given changing needs of clients and communities...." (Letts et al. 1999). Other research on effective nonprofits points to the need for "aggressive interaction with the outside world" (Light 2002) and the need to collaborate with other organizations. NHHK has worked to remain informed by developing and building extensive relationships. This capacity has been repeatedly exemplified by NHHK. For instance, from the early days when Tricia Brooks and the one other NHHK staff member traveled around the state to meet with potential partners, through the extensive work developing these partnerships, to current efforts to improve the application process, the corporation has connected to New Hampshire communities and the health care system, from school nurses to hospital executives. The mission has been central to these efforts. NHHK has consistently worked hard to identify partners and develop relationships with them. These partnerships are key for the achievement of the mission and for diversifying the funding base, another factor identified by the literature on high performing nonprofits (Light 2002).

At the outset, before SCHIP, NHHK established partnerships with private insurers in the state such as Blue CrossBlue Shield (now Anthem). With the infusion of resources brought about by SCHIP, these partnerships were expanded to include physicians, hospitals, community health centers, and schools throughout the state. Partnerships with physicians and hospitals, in particular, were important in making health care available at reasonable rates for the enrolled children. NHHK CEO, Tricia Brooks, worked directly with health care providers to establish discounts and also persuaded the insurance provider to waive administrative costs for all Healthy Kids programs. Some respondents strongly emphasized this fact:

"...Much success of the program can also be attributed to the provider discounts that Tricia [Brooks] has been able to negotiate. [I wonder] if any other bidder...could possibly get the same discounts."

“...NHHK has certain discounts with providers that save the program money. In other words, NHHK contracts directly with certain providers, lots of them, hospitals and community health centers and personal providers that save the program about $\$ 20$ per member per month, which is a lot of money every year." 
The working relationship with DHHS is central to the NHHK public-private partnerships. Interviewees indicated that the partnership is so seamless that some key players in the state believe that NHHK has total authority to change fundamental features of coverage. This is not the case. An example is provided by the determination of eligibility requirements. DHHS and the state legislature have the authority to set eligibility requirements (i.e., the income level for eligibility), not NHHK. A consequence of this misperception is that opponents of the eligibility limit, who think it either too generous or not generous enough, mistakenly hold NHHK responsible.

The public-private partnership has also included foundations in the state. An important example is the role of the Healthy New Hampshire (HNH) Foundation in providing the state match for SCHIP in its first years, prior to the legislature providing such funds. With rising enrollments, however, it soon became clear that $\mathrm{HNH}$ could not provide a sustainable match. With prompting from Governor Shaheen, the state legislature approved funding to continue the program. Commenting on the net impact of some of these partnerships, one of our respondents stated: "There was a unique partnership going on: provider discounts, foundation support, Anthem contribution, and parent premiums. This was a different kind of partnership that made New Hampshire Healthy Kids unique."

While some of NHHK's partnerships were focused on improving their capabilities and processes, others were aimed at expanding the reach of the organization, for instance, the partnership with the NH school system. Partnerships with schools were and are vital for outreach efforts. School nurses, in particular, have been key partners with NHHK.

According to Tricia Brooks, the schools are "tremendously important" partners to NHHK, and school nurses are the contacts for NHHK and families. While not all families cross paths with Family Resource Centers or Community Health Centers, they will at some point interact with the school system. To study this important partnership in more detail, we conducted a survey of all school nurses in the state. ${ }^{7}$

NHHK has been very successful in efforts to inform school nurses about the program. Our respondents were either very (45 percent) or somewhat (55 percent) familiar with Healthy Kids. We also asked the nurses how they had learned about the program. The responses reveal that the efforts of NHHK staff are the most effective in educating school nurses about the program and program changes (see Table 1). The nurses also report significant contact with NHHK: 79 percent have communicated with NHHK within

\footnotetext{
${ }^{7}$ The UNH Survey Center conducted a web-based survey of 536 school nurses throughout the state of $\mathrm{NH}$ consisting of a mixture of multiple choice and open-ended questions on features of the program. The listserv of school nurses was provided by a School Health Services Consultant at the NH State Department of Education. The final response rate was 45\% ( $\mathrm{N}=244)$.
}

Table 1. Responses to Survey Questions Regarding How School Nurses Learn about the Healthy Kids Program and Program Changes

\begin{tabular}{lc}
\hline How School Nurses Learned about Healthy Kids & Percent \\
\hline Promotional materials & 84 \\
Direct contact with NHHK & 72 \\
School personnel & 28 \\
School Nurse listserv & 26 \\
School Nurse Association & 24 \\
Other & 11 \\
\hline How School Nurses Learn/Stay Informed & \\
about Changes to Healthy Kids Programs & Percent \\
\hline Updated materials from NHHK & 79 \\
Contacted by NHHK & 47 \\
School Nurse listserv & 37 \\
Have not learned of changes & 12 \\
Other & 6 \\
Training sessions & 4 \\
\hline
\end{tabular}

Source: School Nurses Survey, UNH Survey Center

the past year, and 77 percent report having a particular staff contact person at NHHK. The brochure that NHHK publishes is an important means by which the nurses communicate to parents about the program; 94 percent of the nurses display these brochures in their offices. The nurses also make important contributions by referring those who might be eligible for the program; 81 percent of the nurses surveyed report having made referrals to the program during the past year.

\section{Conclusions and Policy Recommendations}

New Hampshire has demonstrated a commitment to and success in providing health insurance coverage for children. There is broad public support for insuring children, the state enjoys a high percentage of employer-sponsored insurance, and the public and private investment in the Healthy Kids model has added significantly to the state's Medicaid program to insure children in low and moderate income families. NHHK has distinguished itself as a high performing, mission-driven nonprofit organization that has developed effective partnerships throughout the state to further its goal of providing insurance for all New Hampshire children. There is much praise in these efforts. More than 70,000 children are covered by Healthy Kids programs. 
Yet significant challenges remain to identify and enroll the remaining 17,000 children in the state who are estimated to be uninsured. Based on the research reported here, we make several policy suggestions to address these challenges.

Reauthorization of SCHIP. The U.S. Congress will address the issue of the reauthorization of SCHIP in the current legislative session. It is essential that this important program be reauthorized at a level adequate to maintain current coverage and expand coverage for eligible children. In New Hampshire, we are fortunate that SCHIP funds have not been exhausted, as they have in some other states. Given the impact of SCHIP on coverage through Healthy Kids, it is clear that this partnership with the federal government is crucial for the continued coverage of low to moderate income children in New Hampshire.

Support for aggressive outreach. One of the success stories of NHHK has been the effectiveness of its outreach efforts. Not only have these efforts helped identify and enroll the 7,000 children currently in Healthy Kids Silver, but these efforts have also contributed to the enrollment of eligible children in Healthy Kids Gold. Funds to support even more aggressive outreach ${ }^{8}$ activities would help to identify and enroll the remaining 17,000 uninsured children. This is especially important given the increasing diversity in the state, and the ensuing challenges that a more diverse population present to the program and the health care system.

Further integration of Gold and Silver. We have argued that the partnership between NHHK and DHHS has been important in the effectiveness of their combined efforts to insure children. Further, the integration of Medicaid and NHHK under the one Healthy Kids "brand" has helped in disseminating information about publicly supported health insurance for children. Maintaining and advancing this partnership would build on the current seamless approach.

Incentives for employer-sponsored insurance. As we have pointed out, New Hampshire has a very high rate of employer-sponsored insurance. Even here, however, changes in the health care system have affected the ability of employers to offer health coverage. There are indications of slippage in this type of coverage. Although this is not a recommendation about NHHK per se, further reduction in ESI could overwhelm the capacity of Healthy Kids programs to provide coverage. The state should consider incentives that could help employers offer insurance to employees at a rate both the employers and the employees can afford. ESI will continue to be a vital part of the mix of insurance for New Hampshire's children.

\footnotetext{
${ }^{8}$ It is recognized that there is a $10 \%$ limit of federal SCHIP funds for outreach purposes, and thus, this recommendation is meant to encompass private and state funds as well.
}

State funds for the coverage of children. Finally, success in providing coverage for all eligible uninsured children will depend on the availability of funds. While NHHK has a diverse funding base, it is unlikely that private sources alone would be sufficient to cover all eligible children. Given the broad support in the state for such coverage, additional state funds for health insurance for children should be a high priority. 


\section{References}

Dubay, Lisa, Ian Hill and Genevieve Kenney. 2002.

"Five Things Everyone Should Know About SCHIP." New Federalism: Issues and Options for States, Series A, No. A-55, Washington DC: The Urban Institute.

Freedman, S.A., B.R. Klepper, R.P. Duncan and S.P. Bell 3rd. 1988. "Coverage of the Uninsuredand Underinsured. A Proposal for School Enrollment-Based Family Health Insurance." New England Journal of Medicine 318(13):843-847.

Kenney, Genevieve and Debbie I. Chang. 2004. "The State Children's Health Insurance Program: Successes, Shortcomings and Challenges." Health Affairs 23(5): 51-62.

Letts, Christine W., William P. Ryan and Allen Grossman. 1999. High Performance Nonprofit Organizations: Managing Upstream for Greater Impact. New York: John Wiley \& Sons, Inc.

Lewit, Eugene, M., Courtney Bennett and Richard E. Behrman. 2003. "Health Insurance for Children: Analysis and Recommendations." The Future of Children 13(1): 5-30.

Light, Paul C. 2002. Pathways to Nonprofit Excellence. Washington DC: Brookings Institution Press.

Henderson, Tim and Jerry Coopey. 2000. "The State Children's Health Insurance Program: How Well Is It Working in Rural Areas?" National Conference of State Legislators (NCSL): Rural Health Brief.

State Health Access Data Assistance Center (SHADAC). 2001. "The Current Population Survey (CPS) and State Health Insurance Coverage Estimates." Issue Brief, March 2001/Issue 1, University of Minnesota School of Public Health: A Health Data Resource for States.

U.S. Bureau of the Census. 2005. CPS Annual Demographic Survey: March Supplement. Washington, DC: U.S. Bureau of the Census.

\section{A U T H OR S}

SALLY WARD is Professor of Sociology at the University of New Hampshire and a Senior Fellow with the Carsey Institute. SARAH SAVAGE is a fifth year PhD student in Sociology and a research assistant at the Carsey Institute. Nena Stracuzzi is a Post-Doctoral Research Fellow at the Carsey Institute.

\section{A C K N O W L E D G E M E N T S}

The Carsey Institute at the University of New Hampshire was contracted by the Endowment for Health to conduct this research. The authors thank Robert McGrath, School of Health and Human Services, University of New Hampshire, and Tom Bunnell, Director of the Health, Law and Ethics Institute at Franklin Pierce Law School, for their reviews. For serving as a resource, the authors would like to thank Cindy Mann, Research Professor at Georgetown University, Health Policy Institute. For assistance and cooperation with the school nurse survey, the authors thank Katherine Rannie, RN, MSc, School Health Services Consultant for the New Hampshire State Department of Education. NHHK staff provided valuable data and descriptive material on their programs. For their editorial assistance and suggestions, we thank Barbara Ray, and Amy Seif and Mil Duncan of the Carsey Institute. 


\section{$\triangle$ UNIVERSITY \\ Ail of NEW HAMPSHIRE}

\section{CARSEY}

Building knowledge for families and communities in the 21st Century.

The Carsey Institute at the University of New Hampshire conducts independent, interdisciplinary research and communicates its findings to policymakers, practitioners and the general public.

Huddleston Hall

73 Main Street

Durham, NH 03824

(603) 862-2821

www.carseyinstitute.unh.edu

This brief is part of a series of Carsey Institute Reports on Changes in New England. 